\title{
RESUME OF ROOT-CANAL PROBLEMS AND A PRACTICAL ASEPTIC TECHNIC
}

\author{
By EDOUARD M. HALL, D.D.S., Kansas City, Missouri
}

(Read before the American Dental Association, Los Angeles, California, July 17-21, 1922)

"T HERE is in human affairs one order which is best. That order is not always the one which exists, but it is the order which should exist for the greatest good of humanity. God knows it and wills it; man's duty is to discover and establish it."

If the above quotation were ever applied to a given subject it surely is apropos to the root-canal problem. As a profession if we are even to keep pace with the onward march of civilization, let alone foster the ambition to discover truths in advance of our time, we must delve into those fundamentals of science that go to make up the sum total of that phenomenon called life.

No subject before the dental profession has been more widely and generally discussed in recent years than has the rootcanal problem. I am fully aware that "all that is good has been said before, all that is noble has been thought before," but I challenge you, does there remain a less need for resaying the good and rethinking the noble? So it is with the root-canal problem; while some few have gone to extremes, the vast majority of dentists have as yet made little effort to meet the problem of scientifically treating and filling root-canals.

In meeting with the members of the dental profession in different parts of the United States, Canada, and Mexico, I have been impressed with, and depressed by, the evidence that the rank and file of the profession are still chiefly interested in reparative work upon the exposed portions of teeth and where a root-canal operation is undertaken it is still being done in much the same old way.

't he distressing and most serious feature in this great problem is the indifferent and even antagonistic attitude taken by altogether too many operators toward easily proven and generally acknowledged principles of root-canal technic. One is confronted with the sad fact that the mere knowledge of the truth about root-canal work is not the cure for the evils thereof. "If to do were as easy as to know what to do, then all of us would mount to greater heights."

Our new responsibility as a branch of the healing art, having to deal with mouth infections in their close relation to systemic disease, seems to rest lightly upon the mind and conscience of altogether too many dentists. Many of these same indifferent operators have held up their hands in "holy horror" and loudly protested against the ruthless extraction of teeth, yet in their daily practice they are doing root-canal work in such an unscientific and careless way as to add justification to one hundred per cent vitality propaganda.

If I had to choose between the radical one hundred per cent vitality group of men and those thousands of operators who are still doing root-canal work in much the same way as of old, I would unhesitatingly join the one hundred per 
cent vital group. This does not mean that $I$ believe in the ruthless extraction of all pulpless teeth, as many of you well know, but of the two groups named they do vastly less harm.

It is universally admitted by practically all individuals and institutions worthy of recognition, that all pulpless teeth are not necessarily septic and therefore, all pulpless teeth need not be extracted. It is a source of great personal satisfaction to be able to tell you that many of those of so-called radical tendencies have largely modified their views and the number agitating wholesale removal of all teeth which have lost their pulps or which have exposed pulps, has markedly decreased.

As the subject of my paper implies, I think it well worth while for us to very briefly take a backward glance at the various stages or transitional periods in root-canal work. Let us observe and study conditions before and after our various struggles and encounters with the "Black Beast" of dentistry, as Dr. Fred Molt dubs the pulpless tooth.

In the years 1912 to 1915 when the disclosing power of the X-ray began to attract a widespread attention to diseased conditions about root ends of pulpless teeth, we as a profession, were surprised and chagrined to discover or have revealed how miserably we had failed in our attempts to fill root-canals. Naturally these discoveries were followed by a feverish activity in broaching and instrumentation to open up root-canals so that a filling could be accomplished that would make a good X-ray picture. During this time we were seeking some magic remedy, some heroic germicide which when sealed in a root-canal would destroy all pathogenic organisms and leave the tooth when filled in a satisfactory condition ever afterward.

Is it any wonder that this period of excessive instrumentation coupled with heroic drugs was accompanied by much soreness and suffering on the part of the patient, and in many cases the ultimate loss of teeth, so that the grief associated with root-canal work at this time was enough to discourage all but the dauntless.

Then in 1915 and 1916 Dr. Callahan and others brought forcefully to our attention the then discouraging facts about multiple foramina, and accessory canals, etc. At this time we were trying by heroic methods to clean out all these multiple formations with sodium potassium paste, sulphuric acid, etc. Arguing that you could not fill a canal until all organic matter was removed; then by strenuous pumping and plugging it was hoped to fill all formina, etc., with chlora percha, chlora rosin, and what not, believing that a considerable excess filling or so-called, encapsulation was better than to fail to reach the root end. Some favored the use of $\mathrm{H}_{2} \mathrm{SO}_{4}$ and condemned sodium potassium paste, others believed in sodium potassium paste and condemned $\mathrm{H}_{2} \mathrm{SO}_{4}$, and so on down the list of the old classic remedies.

Then there were those who had not preached or proclaimed in favor of any remedy or method in particular but who earnestly studied and observed the situation and began to have doubts about the value of and merit in these methods.

In 1917 at the national meeting in New York City, we were told in a report from our research department upon the relative efficiency of medicaments for the sterilization of tooth structure, that no medicament sealed in an infected tooth would sterilize same and would after a few hours become septic itself; that where clinical results had seemingly been successful it was probably not because of but in spite of treatment used and was in fact a matter of toleration due to natural resisting powers of the patient. This was the period of greatest turmoil and at this time the so-called one hundred per cent vitality propaganda was at its zenith. However, this was also the turning point in the line of study and investigation. We began turning from heroic in- 
strumentation and medication, to a closer observation of the biologic phase.

When the startling facts and conditions associated with the pulpless tooth were first revealed to us, we were distressed to learn that clinical examination and observation as followed in the past had failed to meet requirements. So the pendulum swung over to the extreme and we went through a period of ultra scientific laboratory research.

It did not take long to discover that the problems having to do with the reactions associated with living tissue cells could not all be answered by laboratory tests. As Dr. Noyes says, "Laboratory work can only clarify the principle upon which clinical judgment and procedure are based." The most valuable and the most hopeful developments in the pulpless tooth problem are the results of histological investigations that in recent years have gone beyond laboratory study to a correlated clinical observation of vital biologic phenomena.

For many years we have been told that the pulp had no recuperative powers, that it had neither resistance nor repair. Recent investigations seem to prove that, if the pulp is not overwhelmed by infection, it has both resistance and repair to a very marked degree. So much so that pulpotomy instead of pulp extirpation may prove to be the better procedure. Yet we believe the evidence favors the removal of the entire pulp to the natural constriction of the canal at or very near the cemento-dentinal juncture. Where this is done without injury to apical tissues either with instruments or drugs, it seems rational to believe that multiple foramina and coronary openings will be closed by a throwing down of cemental tissue and thus the tooth be left in a physiologic condition.

Instead of seeking germicides to seal in a tooth and thus destroy invading bacteria, the vital, biologic conception is to evacuate and remove, without tissue trauma, all septic matter possible and thus change the balance of power from infection to immunity. We do not wish to be understood as advocating or preaching antiseptic nihilism but we believe the lethal effect of most of the old classic germicides on the animal cells, with the clinical results of retardation and inhibition of the natural processes of repair, are becoming so well recognized that their use is contraindicated.

The chlorine preparations, or the socalled Carrell-Dakin remedies, in their aqueous solutions, in such weak dilutions as to have little value as germicides in laboratory tests, in clinical application seem to supply some element to living tissue cells that carry them from a condition of susceptibility to one of immunity.

We believe the evidence justifies the conclusion that the only pulpless tooth that can with safety be retained in the mouth is one having vital cementum and pericementum. Where these tissues have become necrotic either from infection, drugs, or trauma we believe it is a case of toleration where they are retained even though a process of sterilization is accomplished. Clinical observation seems to indicate that these sterilized necrotic root ends are susceptible areas for metastatic infection that simply remain dormant any where from a few months to several years according to the vitality of the patient and the element of chance infection.

This does not mean that all teeth presenting with a history of disease or radiographic evidence of involvement of supporting tissues, must necessarily be extracted, but it does mean that the evidence must favor the assumption that the periodontal membrane is still intact and the patient's health good and such as to make the risk of treatment justifiable.

The problem of greatest importance, as $I$ see it, is not how to save teeth presenting with a history of disease, but how to handle new root-canal operations so as to prevent apical and periapical infection. Of course, prevention of the need of pulp extirpation through prophylaxis is the keynote of modern dentistry, 
but during the rest of our lives and for many generations to come every practicing dentist will often be face to face with the necessity of either doing a root-canal operation or extracting the tooth.

Pulp conservation is a phase of the problem that is very hopeful in its outlook, yet it will require years of clinical history and observation to procure evidence that will be dependable guidance in our efforts to save exposed or nearly exposed pulps.

Applying the biological facts, as related to vital cementum and pericementum, we believe root resection, or apicoectomy, is an unscientific operation and is a matter of tissue toleration dependent upon the vital resistance of the patient. Until some technic can be perfected that will seal the dentinal tubuli of the resected tooth (as with metallic silver), without vital tissue damage, we believe, working under the Golden Rule, that results obtained do not justify the operation.

I do not wish anything that I may say to cause anyone to think that I do not believe in laboratory or other means of research for they are very valuable and are necessary as a means of checking up on clinical work, but in the final analysis any procedure or technic will have to stand or fall according to clinical results obtained.

I do not think for a moment that I know the correct answer to all root-canal problems, and I don't believe anyone else does at this time, and ten, fifteen or twenty years from now we will know little more than we do today unless our work is systematized and hundreds of skilful, intelligent men keep a very carefully tabulated series of clinical case records.

To give as proof for or against certain procedure or technic, deductions arrived at from X-ray studies of old root-canal work is not fair or just because the work was done under what we now recognize as very unfavorable conditions, where tissue destroying drugs were used and asepis was unknown. For example, an $\mathrm{X}$-ray of a tooth with seemingly perfect root filling yet showing destruction of supporting tissues is no argument against root-canal work, because the condition was probably the result of heroic drugs and a lack of asepsis. We must make deductions from a mass of evidence from carefully tabulated records of work done according to present standards of .easily proven better methods.

\section{SUMMARY}

1. The value and importance of the vitality and health of apical tissues cannot be overstated.

2. No tissue destroying drugs are safe to use in root-canal work. Therefore, no pulp should be devitalized, as with arsenic.

3. Pulp extirpation should be performed under general anesthesia, nerve block or pressure anesthesia after treatment.

4. A definite point in a root-canal should be determined by measurement, at which to stop operative effort and all instrumentation must be controlled according to this measurement. The ideal place for this seems to be the cemento-dentinal juncture.

5. Decision as to the extraction or retention of questionable teeth should be based upon a most careful diagnosis, in which the health of the patient is a deciding factor.

6. Dental diagnosis requires a thorough knowledge and use of the X-ray electric pulp test, and transillumination, with every other aid that will help discover all teeth with non-vital pulps and determine as nearly as possible the condition of the teeth themselves and the health or disease of supporting tissues. (Where indicated the patient's physical condition should be passed upon by a medical practitioner.)

7. The protrusion of filling beyond end of root is very undesirable and should be avoided as much as possible.

8. Infection is probably the greatest 
factor causing failure in root-canal work. Therefore the importance of

\section{An Aseptic Technic}

Infections in and about the root ends of teeth must come from one of two sources, either by metastasis or by direct implantation in and through the rootcanal. Since a study of thousands of $\mathrm{X}$-rays of teeth reveals the fact that almost all of these infections are associated with teeth upon which a root-canal oper-

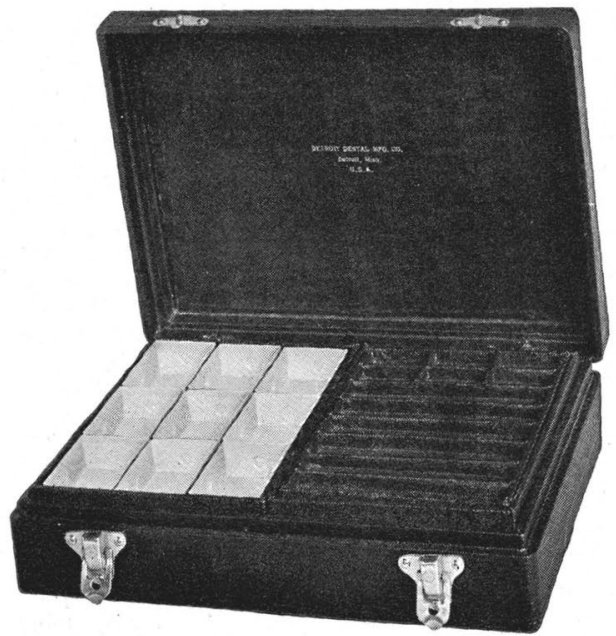

Fig. 1

ation has been performed or one in which caries has exposed, or nearly exposed the pulp, we believe it is logical to conclude that practically all periapical infections are the result of direct implantation in and through root-canals. Therefore, one of the most important things in rootcanal work is a practical aseptic technic.

Success in root-canal work requires, first of all, that the operator have within quick and easy reach an abundant supply of the many small instruments and materials that are to be used in the operation-all in an aseptic condition.

The variety and quantity of these instruments and materials calls for special provision and equipment to properly take care of them. The Detroit Dental Man- ufacturing Company is making a pulpcanal instrument case having many compartments which admirably take care of these supplies (Fig. 1). This case has a classified arrangement with the idea of quick and easy access to the diversified instruments and materials required, all of which when put into the case in a sterile or aseptic condition are kept in that state by the use of formaldehyde, provision for which is made in the case. Thus the case is not only a container of instruments and materials in the most convenient arrangement, but it is at the same time a means of keeping sterile and ready for use an abundant supply of all

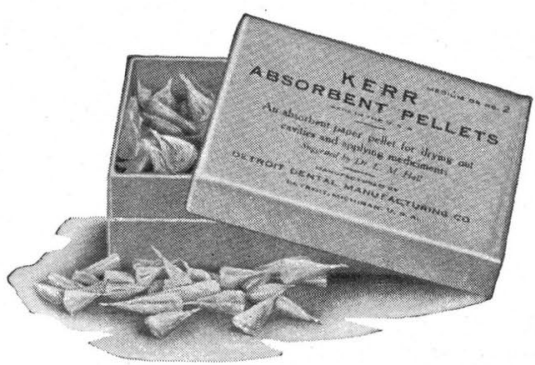

Fig. 2

instruments and materials needed in a root-canal operation.

All dressings, as well as instruments, must of course be sterile. For applying medicaments to or drying out carious cavities and pulp chambers we use absorbent pellets (Fig. 2), which are made in assorted sizes-small, medium and large. All of these dressings we dry bake as follows: they are placed in Xray film boxes according to sizes then these film boxes without lids are placed in an ordinary Nabisco wafer tin box and the lid or cover put on, thus they are ready for baking, which of course must be in an insulated oven without direct contact with flame or heating unit (Fig. 3). A thermometer should be inserted so the bulb will be just above the box containing the dressings. The oven temperature should be raised to $265^{\circ} \mathrm{F}$. for a minimum of fifteen minutes. 
Care must be taken not to run the oven temperature above $270^{\circ} \mathrm{F}$. at any time or dressings may be scorched and damaged. These dressings are prepared in quantity in this manner and then trans- effective. This has led to the development of the Kerr alcohol sterilizer (Fig. 4) which has three shallow wells for short or Style B broaches, three deep wells for long or Style D broaches, and

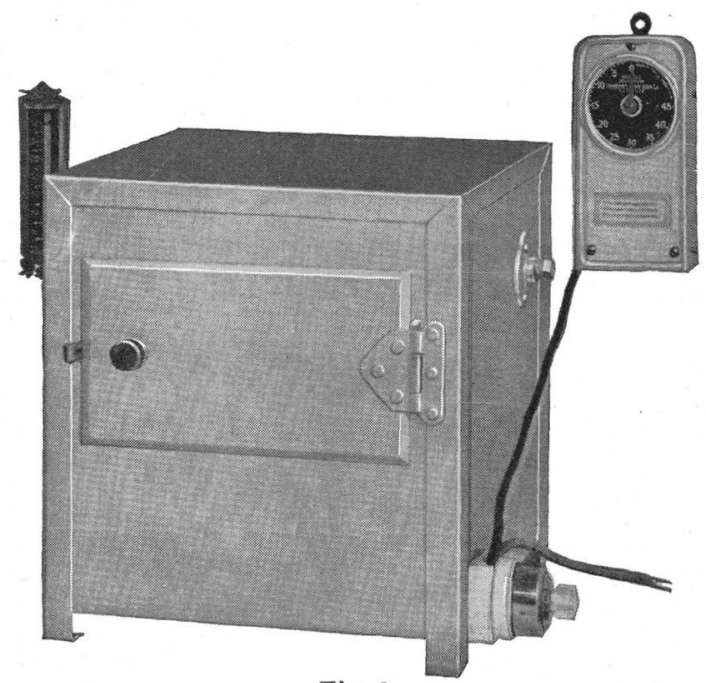

Fig. 3

ferred to the Kerr pulp-canal instrument case and kept under formaldehyde.

Gutta-percha points are sterilized in quantity by dropping into tincture of iodin for five minutes, then into alcohol five minutes and then transferred to the Kerr pulp-canal case.

New broaches, particularly barbed

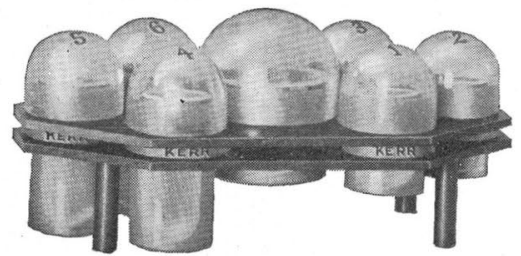

Fig. 4

broaches, are dangerous until tested by using; quite often a weak spot in a broach is not discovered until a part of it is left in a root-canal, so it is quite desirable to be able to use a good broach over and over again as long as it is a large central well for dipping mouth mirrors, rubber-dam clamps, etc., for alcohol flaming (Fig. 5). Scissors, pliers, pluggers, etc., can be dipped in deep wells for sterilizing and flaming.

When you make preparation for a root-canal operation you select a series of three succeeding sizes of broaches to be used and place at least four or five of each size in each succeeding well. The bottom of wells are oval so that points of broaches stand together in center and handles in a semi-circle about the circumference of the wells (Fig. 6).

It must not be conceived that the idea is simply to shake or dip broaches in alcohol for a second or two. The habit should be formed to take the broach standing nearest to you (No. 1 in illustration) from a well and, after using, to mechanically clean and replace it at farthest side of semi-circle (No. 5 in illustration) so that it will remain in alcohol until you have used in turn each 
broach in front of it before you again use it, or a lapse of at least five or six minutes. This same routine applies to the use of short or Style B broaches.

Special emphasis and attention must be given to the mechanical cleaning of broaches before they are replaced in the alcohol bath. First, because the instrument is of little or no value for further use unless it is cleaned, and second, with fill from No. 2 all the other wells and refill No. 2 with fresh alcohol, then No. 3 and No. 4, etc. In other words, don't think that the same alcohol will retain its efficiency forever when exposed to the air and other changes. Each well has a ground glass neck and cover, numbered to match, so that you can keep them covered and preserve the high efficiency of your alcohol.

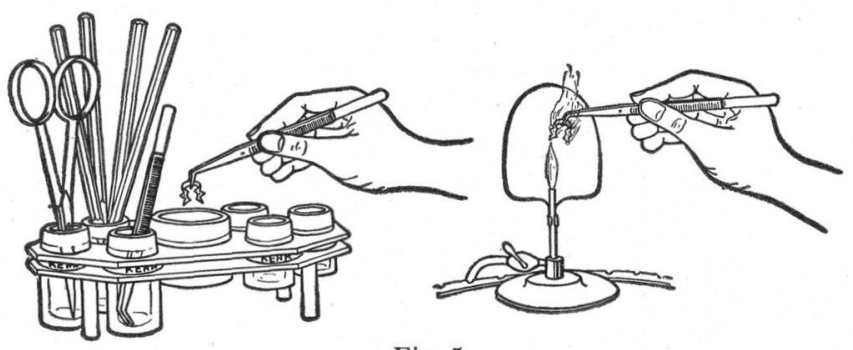

Fig. 5

a mass of bacteria left upon a broach the alcohol would coagulate the outer layer of protoplasmic cells and thus protect, for a longer time than five or six minutes, those cells in the center of the coagulated mass. In this manner five or six minutes in the alcohol would fail to sterilize the broach.

It must not be forgotten that alcohol

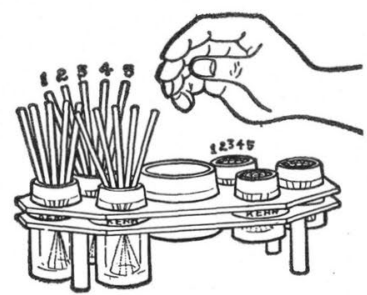

Fig. 6

has a great affinity for moisture out of the air, etc., and you should systematically, by rotation, fill first from No. 1 all the other wells and then refill No. 1 with fresh alcohol. Then the next time
Although 65 per cent to 70 per cent alcohol has greater germicidal efficiency, we recommend the use of 95 per cent grain alcohol in all wells to facilitate flaming and the use of alcohol in rootcanals, etc. Modified solutions for separate special use make trouble in rotating alcohol from one well to another.

Before broaches, etc., are returned to the instrument case the handles should be dipped in alcohol and flamed.

Broaches ready mounted in long and short aluminum handles are much to be preferred over unmounted broaches.

The control of sepsis in the field of operation is best accomplished by first giving the entire mouth a thorough prophylaxis before starting root-canal work; then at each visit from the patient the mouth should be thoroughly rinsed and scrubbed with antiseptic solutions before applying rubber-dam, then tooth and dam should be painted with iodin, followed by fifty per cent sodiphene and field dried with alcohol. 